\title{
Nitric Oxide Inhibition of Tobacco Catalase and Ascorbate Peroxidase
}

\author{
Daniel Clark, Jörg Durner, Duroy A. Navarre, and Daniel F. Klessig \\ Waksman Institute and Department of Molecular Biology and Biochemistry, Rutgers-The State University of \\ New Jersey, 190 Frelinghuysen Road, Piscataway 08854-8020, U.S.A. \\ Accepted 2 September 2000.
}

We used a variety of nitric oxide (NO) donors to demonstrate that NO inhibits the activities of tobacco catalase and ascorbate peroxidase (APX). This inhibition appears to be reversible because removal of the NO donor led to a significant recovery of enzymatic activity. In contrast, APX and catalase were irreversibly inhibited by peroxynitrite. The ability of NO and peroxynitrite to inhibit the two major $\mathrm{H}_{2} \mathrm{O}_{2}$-scavenging enzymes in plant cells suggests that NO may participate in redox signaling during the activation of defense responses following pathogen attack.

In response to infection by an avirulent pathogen, plants defend themselves by activating a battery of resistance responses aimed at limiting pathogen ingress (Hammond-Kosack and Jones 1996). These responses may include a rapid increase in the levels of reactive oxygen species (ROS) known as the oxidative burst $(\mathrm{OB})$, the strengthening of cell walls, the synthesis of salicylic acid (SA), and the accumulation of several families of pathogenesis-related proteins. In addition, plant disease resistance is often associated with the formation of a hypersensitive response (HR) in which necrotic lesions develop at the infection sites and the pathogen is restricted to these sites. Later, a long-lasting, systemic acquired resistance (SAR) to a broad array of pathogens develops in the uninoculated parts of the plant.

Although we still await a complete picture of the events involved in defense-response activation, SA has been implicated as a critical signal in this process (Dempsey et al. 1999). Various studies have suggested that $\mathrm{H}_{2} \mathrm{O}_{2}$ and other ROS also are involved (Dangl 1998; Van Camp et al. 1998). For example, high levels of $\mathrm{H}_{2} \mathrm{O}_{2}$ trigger cell death in soybean suspension cells, whereas lower levels induce defense gene expression (Levine et al. 1994). In addition, inhibiting the OB prevents SAR development in Arabidopsis spp. (Alvarez et al. 1998). Conversely, constitutive elevation of ROS levels enhances defense gene expression and disease resistance in several plant species (Alvarez et al. 1998; Chamnongpol et al. 1996;

Corresponding author: D. Klessig; Fax: +1-607-254-6779;

E-mail: dfk8@cornell.edu

Current address of J. Durner: Institute of Biochemical Plant Pathology, GSF-National Research Center for Environment and Health, D-85764 Oberschleissheim, Germany.

Current address of D. F. Klessig: Boyce Thompson Institute for Plant Research, Tower Road, Ithaca, NY 14853, U.S.A.
Chamnongpol et al. 1998; Takahashi et al. 1997; Wu et al. 1995; Wu et al. 1997).

The relationship between SA and ROS in the defense signaling pathway is currently unclear. SA was shown to inhibit the activity of catalase and ascorbate peroxidase (APX) (Chen et al. 1993; Durner and Klessig 1995; Durner and Klessig 1996), which are the predominant $\mathrm{H}_{2} \mathrm{O}_{2}$-scavenging enzymes found in plant cells. It was therefore proposed that increases in $\mathrm{H}_{2} \mathrm{O}_{2}$ (and other ROS) work downstream of SA as second messengers for activating defense responses. Consistent with this possibility, SA was shown to potentiate the OB as well as cell death in soybean suspension cells (Shirasu et al. 1997). However, other studies have suggested that $\mathrm{H}_{2} \mathrm{O}_{2}$ functions upstream rather than, or in addition to, downstream of SA (Dempsey et al. 1999). To account for these somewhat contradictory results, it was recently proposed that SA and $\mathrm{H}_{2} \mathrm{O}_{2}$, along with cell death, form a self-amplification loop, termed the oxidative cell death (OCD) cycle, that signals the activation of defense responses (Van Camp et al. 1998).

In addition to $\mathrm{SA}$ and $\mathrm{H}_{2} \mathrm{O}_{2}$, recent studies have suggested that nitric oxide (NO), an important signaling molecule in mammals, plays a key role in activating disease resistance in plants (Delledonne et al. 1998; Durner et al. 1998). NO synthase-like activity was shown to increase in tobacco successfully resisting infection with tobacco mosaic virus. Furthermore, artificially generated NO induced defense gene expression via signaling pathways that likely involve cyclic GMP and cyclic ADP ribose (Durner et al. 1998; Klessig et al. 2000). NO also potentiated ROS-induced hypersensitive cell death in soybean suspension cells, and NO synthase inhibitors blocked HR formation in Arabidopsis spp., resisting pathogen infection (Delledonne et al. 1998).

To further elucidate the mechanism(s) through which NO, along with SA and $\mathrm{H}_{2} \mathrm{O}_{2}$, signals disease resistance in plants, we are identifying the direct and indirect targets of NO in tobacco. Recently, NO was shown to activate a tobacco mitogen-activated protein kinase and to inhibit aconitase activity (Kumar et al. 2000; Navarre et al. 2000). Since NO is known to directly bind and reversibly inhibit some mammalian hemecontaining enzymes, we tested whether it also inhibits the tobacco heme-containing enzymes catalase and APX.

Catalase (enzyme nomenclature designation [EC] 1.11.1.6) was purified to homogeneity from tobacco (Nicotiana tabacum cv. Xanthi-nc), as previously described (Durner and Klessig 1996). In the presence of the NO donors $S$-nitroso- $N$ - 
acetyl-DL-penicillamine (SNAP) (Alexis Corp., San Diego, CA, U.S.A.), S-nitroso-L-glutathione (GSNO) (Alexis Corp.), or the short-lived (Z)-1-( $N$-methyl- $N$-[6- $(N$-methylammoniohexyl)amino])-diazen-1-ium-1,2-diloate (NOC-9) (half-life of $3 \mathrm{~min}$ ) (Alexis Corp.), catalase activity was inhibited in a time-dependent manner (Fig. 1A). Activity was measured

A

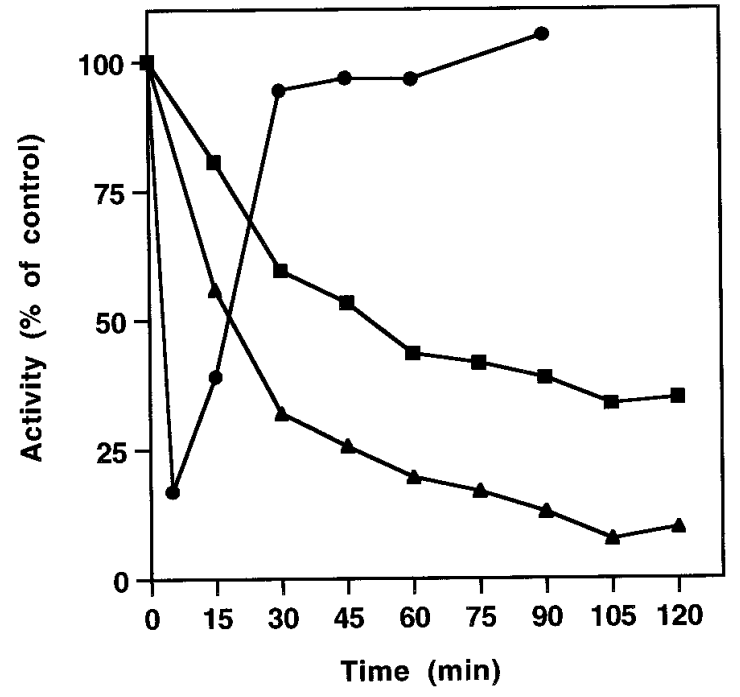

B

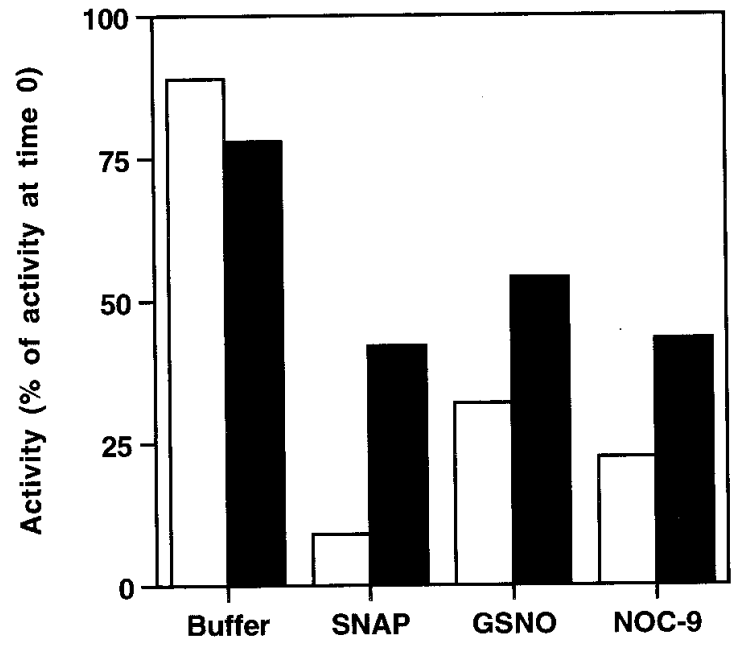

Fig. 1. Reversible inhibition of tobacco catalase by nitric oxide (NO) donors. A, Purified catalase $(4.8 \mu \mathrm{g}$ corresponding to $0.08 \mu \mathrm{M})$ was incubated in the presence of $0.8 \mathrm{mM} S$-nitroso- $N$-acetyl-DLpenicillamine (SNAP) or $S$-nitroso-L-glutathione (GSNO) or $2.5 \mathrm{mM}$ (Z)-1-( $N$-methyl- $N$-[6-( $N$-methylammonio-hexyl)amino])-diazen-1-ium1,2-diloate(NOC-9). A control incubation with $50 \mathrm{mM}$ potassium phosphate buffer, $\mathrm{pH}$ 6.6, was conducted for each time point. Values are expressed as the percentage of the corresponding control activity and represent the mean of at least two assays. Squares $=$ GSNO. Triangles $=$ SNAP. Circles = NOC-9. B, Recovery of catalase activity after removal of NO donors. Samples were pretreated with buffer, $0.8 \mathrm{mM}$ SNAP or GSNO for $120 \mathrm{~min}$, or $2.5 \mathrm{mM}$ NOC-9 for $5 \mathrm{~min}$ and then passed through a NAP-10 or Sephadex G-25 gel filtration column to remove unbound NO donors. Subsequently, samples were incubated for $15 \mathrm{~min}$ in the presence of a $\mathrm{H}_{2} \mathrm{O}_{2}$-generating system consisting of glucose and glucose oxidase, producing $0.1 \mathrm{nmol}$ of $\mathrm{H}_{2} \mathrm{O}_{2}$ per $\mathrm{ml}$ per min (Durner and Klessig 1996). Catalase activity was measured, as described. Values are expressed as the percentage of activity at time 0 prior to the 120 - or 5 -min pretreatment. Open bars = activity after incubation with either buffer or NO donors. Closed bars = activity after buffer exchange. with a Model 5739 commercial oxygen probe (Yellow Spring Instruments, Yellow Springs, OH, U.S.A.), as previously described (Durner and Klessig 1996). After a 120-min incubation at room temperature, inhibitions of 70 and $90 \%$ were observed with GSNO and SNAP, respectively. With NOC-9, a maximum inhibition of $80 \%$ was observed after a 5 -min incubation at room temperature, whereas a complete restoration of activity could be observed after $90 \mathrm{~min}$ (Fig. 1A). The rate and amount of NO-mediated catalase inactivation did not depend on the presence of $\mathrm{H}_{2} \mathrm{O}_{2}$ (data not shown), in contrast to the inhibition of catalase mediated by SA (Durner and Klessig 1996). Removal of NO donors by gel filtration from the samples exhibiting 70 to $90 \%$ inhibition resulted in partial recovery (40 to $50 \%$ ) of enzymatic activity (Fig. 1B).

The treatment of catalase with 3-morpholino-sydnonimine (SIN-1), a peroxynitrite donor, appeared to be irreversible (data not shown). These results are consistent with previous studies demonstrating that NO-mediated regulation is generally reversible when $\mathrm{NO}$ acts directly on the target enzyme but irreversible with the NO-derived species peroxynitrite, nitrogen dioxide, or dinitrogentrioxide (Wink and Mitchell 1998).

In order to determine if the sensitivity of tobacco catalase to NO is similar to that of animal catalases, the concentrationdependent inhibition of tobacco and bovine catalases by NOC9 was assessed (Fig. 2). The corresponding $\mathrm{IC}_{50}$ (concentration of inhibitor necessary to inhibit $50 \%$ of activity) was estimated by a double-reciprocal Lineweaver-Burk plot (Fig. 2). Tobacco catalase appeared to be slightly more sensitive $\left(\mathrm{IC}_{50}=1.6 \mathrm{mM}\right.$, standard error $\left.[\mathrm{SE}]=0.4\right)$ to NOC-9 than its bovine counterpart $\left(\mathrm{IC}_{50}=3.2 \mathrm{mM}, \mathrm{SE}=0.7\right)$.

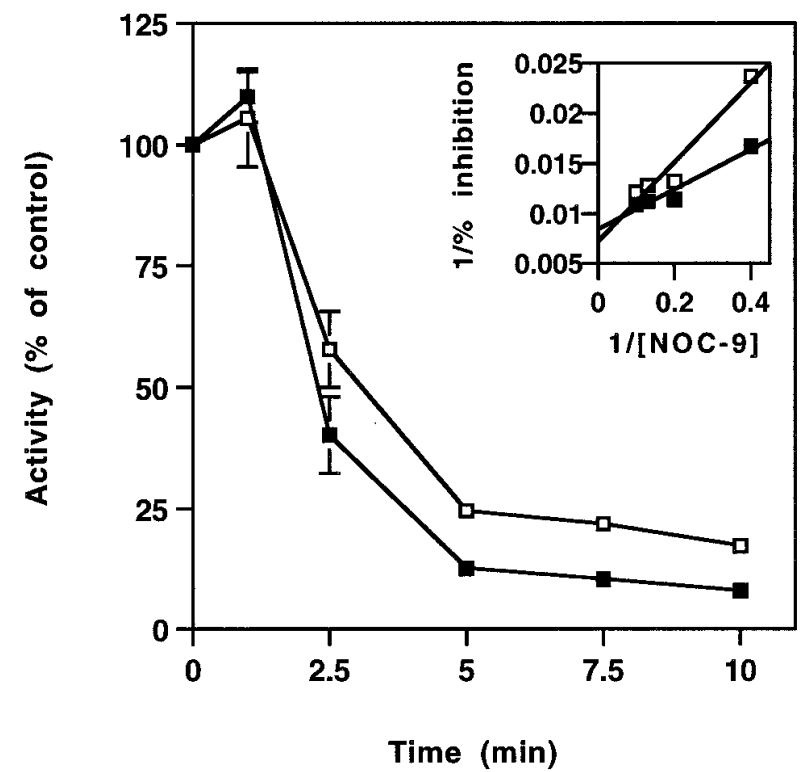

Fig. 2. Concentration-dependent inhibition of tobacco and bovine catalases by (Z)-1-( $N$-methyl- $N$-[6-( $N$-methylammonio-hexyl)amino])-diazen-1-ium-1,2-diloate (NOC-9). Tobacco or bovine catalase (Sigma, St. Louis, MO, U.S.A.) was incubated with $1,2.5,5,7.5$, and $10 \mathrm{mM}$ NOC9 for $5 \mathrm{~min}$ at room temperature, and the activity was measured, as previously described (Durner and Klessig 1996). Values are expressed as the percentage of a buffer-treated control and represent the mean \pm standard error calculated from three independent assays. A double-reciprocal Lineweaver-Burk plot of the data is shown (inset). Closed squares = tobacco. Open squares $=$ bovine. 
In mammals, NO has been shown to reversibly inhibit catalase activity by directly interacting with the heme moiety (Hoshino et al. 1993). To elucidate the mechanism through which NO inhibits tobacco catalase, we examined NO's effects on the formation of various catalase reaction intermediates (Fig. 3), which can be distinguished spectroscopically by their absorption spectra in the Soret (near UV) region. The absorption spectrum in this region for the purified enzyme is shown in Figure 3 (trace 1). The broad peak centered around $405 \mathrm{~nm}$ is consistent with the enzyme existing primarily in an active ferricatalase (Fe III) state. After incubating the enzyme with SNAP for $3 \mathrm{~h}$, activity declined from 64.3 to $6 \mathrm{U} / \mathrm{mg}$, whereas absorbance at 420 to $440 \mathrm{~nm}$ increased (trace 2) and at $405 \mathrm{~nm}$ decreased. This is consistent with a reduction in the amount of ferricatalase (Deisseroth and Douce 1970). The spectral shift could be caused by NO binding to the heme. After removing SNAP and reactivating the enzyme for $15 \mathrm{~min}$ in the presence of small amounts of $\mathrm{H}_{2} \mathrm{O}_{2}$, the absorbance at 420 to $440 \mathrm{~nm}$ decreased and at $405 \mathrm{~nm}$ increased (trace 3), indicating a partial recovery of active ferricatalase. Thus, binding of NO as well as inhibition of catalase activity (Fig. 1) appear to be reversible.

In addition to catalase, the effect of NO on APX (EC 1.11.1.11) was assessed with the use of a crude enzyme extract prepared from tobacco leaves, as previously described (Durner and Klessig 1995). As a result of the likely presence of NO scavengers in this crude preparation, time-course inhibition experiments were performed with NO donors at a final concentration of $5 \mathrm{mM}$. As in the case of catalase, GSNOmediated inhibition of APX was time dependent, with ap-

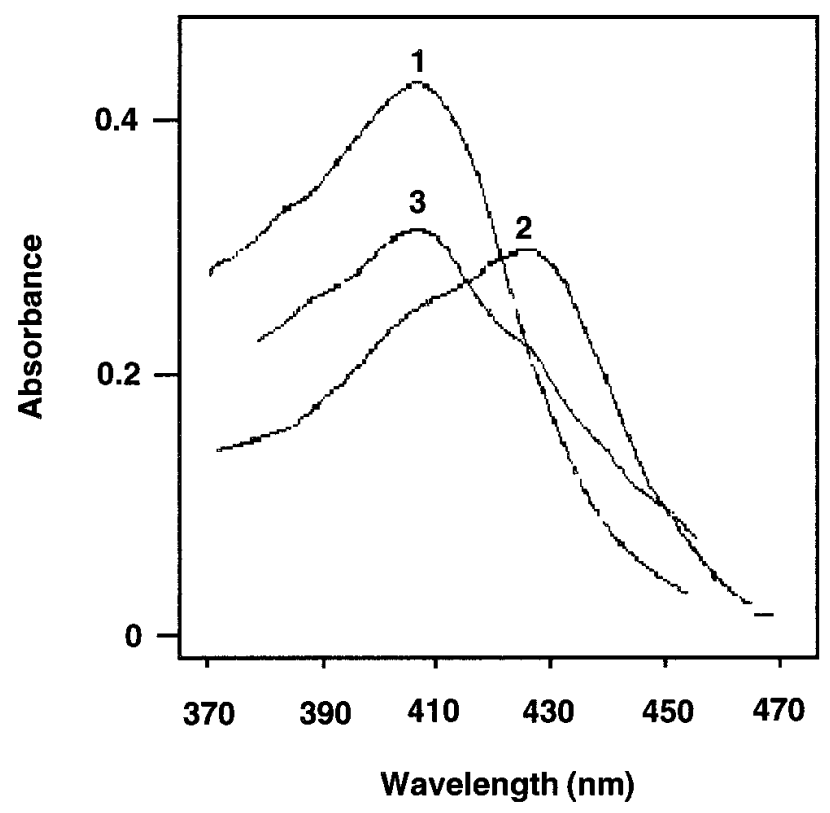

Fig. 3. Nitric oxide-induced formation of an inactive catalase intermediate. The absorption spectrum of catalase was determined under three different conditions. Trace 1 is $2 \mu \mathrm{M}$ of ferricatalase (Fe III), which exhibits a specific activity of $64.3 \mathrm{U} / \mathrm{mg}$. Trace 2 is the formation of a catalase intermediate after incubating the catalase represented in trace 1 with $0.8 \mathrm{mM} S$-nitroso- $N$-acetyl-DL-penicillamine (SNAP) for $3 \mathrm{~h}$. The activity remaining after SNAP treatment was $6 \mathrm{U} / \mathrm{mg}$. Trace $3(27 \mathrm{U} / \mathrm{mg})$ was generated after buffer exchange, dialysis, and reactivation with $\mathrm{H}_{2} \mathrm{O}_{2}$ of the sample in trace 2 . proximately $70 \%$ inhibition detected after a 60 -min incubation at room temperature (Fig. 4A). Longer incubations were avoided because APX is rapidly inactivated at room temperature. Surprisingly, GSNO inhibition of APX was not reversible. Removal of the inhibitor by Sephadex G-25 gel filtration did not result in any recovery of enzyme activity (data not shown). However, it has been reported that the thioredoxin system can cleave GSNO to produce NO and superoxide, ultimately promoting peroxynitrite accumulation (Nikitovic and Holmgren 1996). Since the thioredoxin system is probably
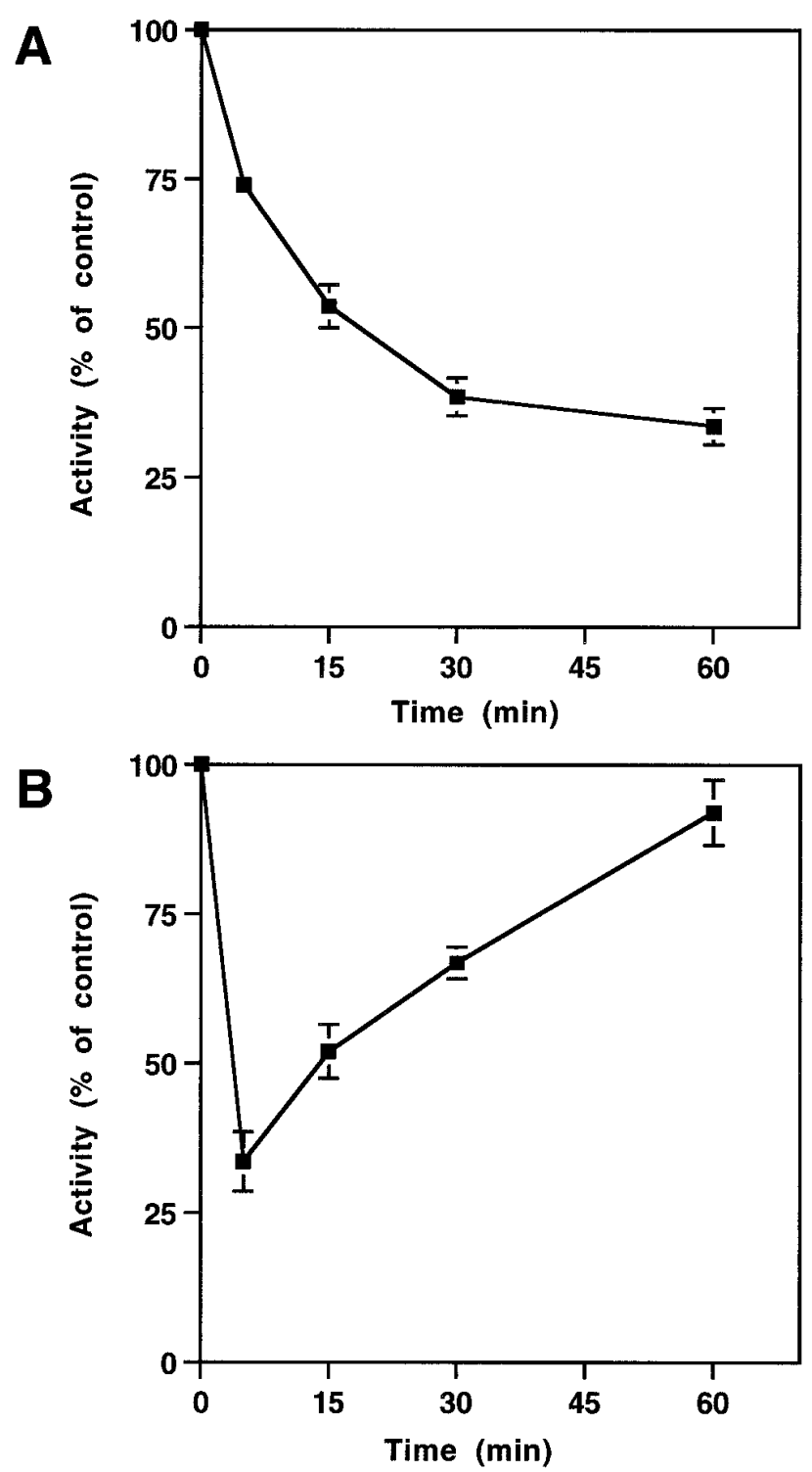

Fig. 4. Inhibition of tobacco ascorbate peroxidase (APX) by nitric oxide (NO) donors. A, A crude enzyme extract was incubated with $5 \mathrm{mM} \mathrm{S}$ nitroso-L-glutathione (GSNO) in $50 \mathrm{mM}$ potassium phosphate buffer, $\mathrm{pH}$ 7 , at room temperature. At the indicated times, APX activity was measured, as previously described (Durner and Klessig 1995). A control incubation without GSNO was conducted in parallel for each time point. Values are expressed as the percentage of the corresponding control activity and represent the mean \pm standard error calculated from three independent assays. B, Same as in A, but $5 \mathrm{mM}(\mathrm{Z})-1-(N$-methyl- $N$-[6( $N$-methylammonio-hexyl)amino])-diazen-1-ium-1,2-diloate was used as the NO donor. 
active in our crude extract, we suspect that the irreversible inhibition of APX by GSNO was mediated by peroxynitrite rather than by NO. Consistent with this possibility, the inhibition of APX by $5 \mathrm{mM}$ SIN-1 also was irreversible (data not shown).

To avoid the potential production of peroxynitrite and gain more insight into the nature of APX inhibition by NO, we utilized the short-lived NO donor NOC-9. A maximum inhibition of $66 \%$ was obtained after a 5-min incubation at room temperature. At $60 \mathrm{~min}$, nearly $100 \%$ of the control activity was restored (Fig. 4B). This behavior, also observed with purified catalase (Fig. 1A), provides a strong argument that NO inhibits catalase and APX in a reversible manner. These results suggest that once liberated, NO is quite unstable under these experimental conditions.

Removing NOC-9 by Sephadex G-25 gel filtration almost completely restored APX activity at all times tested (data not shown), providing further evidence that NO inhibits APX in a reversible manner. The ability of APX and catalase to rapidly regain activity following the removal of NO is consistent with our assumption that these enzymes are inhibited by the formation of an iron-nitrosyl complex between NO and the iron atom of the heme group. Precedence for such an interaction comes from studies of NO-mediated guanylate cyclase activation and the inhibition of cytochrome P450 and catalase in mammals (Brown 1995; Wink and Mitchell 1998). In contrast, the recently described inhibition of tobacco aconitase by NO is likely accomplished by a different mechanism that involves dissociation of the iron-sulfur cluster from the enzyme (Navarre et al. 2000).

Various concentrations of NOC-9 were used to show that NO-mediated inhibition of APX activity is concentration de-

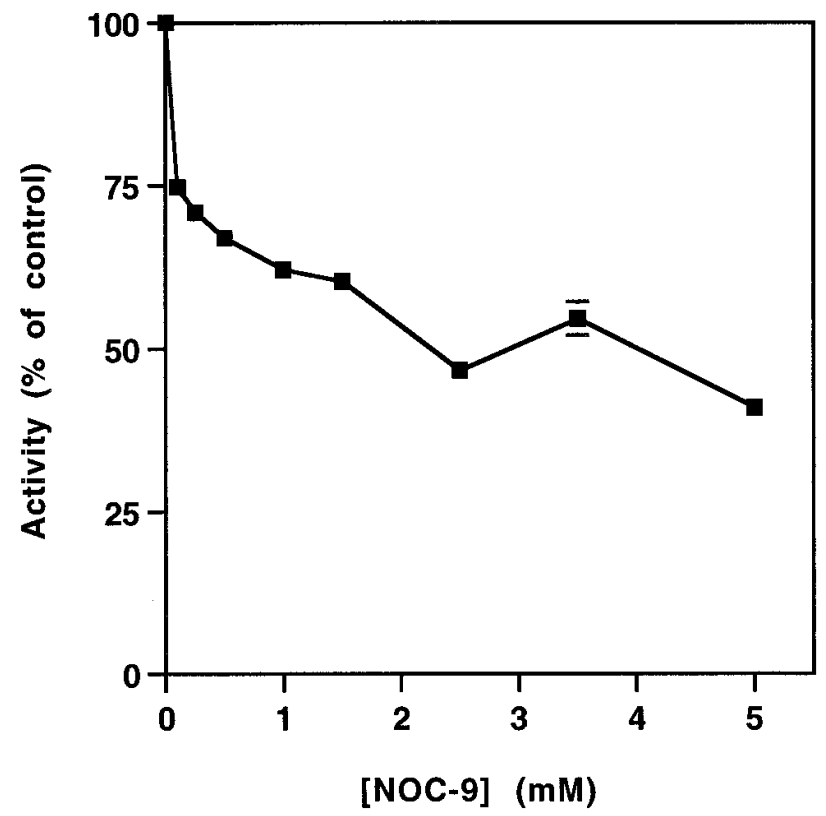

Fig. 5. Concentration-dependent inhibition of ascorbate peroxidase (APX) by (Z)-1-( $N$-methyl-N-[6-( $N$-methylammonio-hexyl)amino])-diazen-1-ium1,2-diloate (NOC-9). A crude enzyme extract was incubated with $0,0.1$, $0.25,0.5,1.0,1.5,2.5,3.5$, and $5 \mathrm{mM}$ NOC-9 for $5 \mathrm{~min}$ at room temperature, and APX activity was measured. Values are expressed as the percentage of a buffer-treated control and represent the mean \pm standard error calculated from three independent assays. pendent (Fig. 5). Following a 5-min incubation at room temperature, approximately $50 \%$ of the inhibition was observed in the presence of $2.5 \mathrm{mM}$ NOC-9. It is currently unclear why higher concentrations of NOC-9 failed to produce significantly greater levels of APX inhibition. However, because plant cells contain several isoforms of APX (Asada 1992), it is possible that only some isoforms are inhibited by NO.

Because catalase and APX are inhibited by SA (Chen et al. 1993; Durner and Klessig 1995; Durner and Klessig 1996), we tested whether the combined presence of SA and NO would synergistically enhance enzyme inhibition. Neither appeared to reproducibly enhance each other's ability to inhibit APX or catalase activity in vitro (data not shown). However, the ability of NO to stimulate SA accumulation in tobacco (Durner et al. 1998) suggests there is a mechanism through which NO could further enhance $\mathrm{H}_{2} \mathrm{O}_{2}$ production in plant cells. Recently a differential effect of $\mathrm{NO}$ on lignification and on $\mathrm{H}_{2} \mathrm{O}_{2}$ production during normal growth and/or pathogen attack has been suggested. NO was shown to inhibit xylem peroxidase from Zinnia elegans (Ferrer and Ros Barceló 1999), although NO did not affect the production of $\mathrm{H}_{2} \mathrm{O}_{2}$ necessary for lignification in the xylem.

On the basis of these results, we propose that NO, like SA, plays a role in regulating $\mathrm{H}_{2} \mathrm{O}_{2}$ levels during the resistance response by reversibly inhibiting catalase and APX. This possibility is consistent with the observation that the timing of $\mathrm{NO}$ accumulation coincides with that of $\mathrm{H}_{2} \mathrm{O}_{2}$ accumulation in soybean suspension cells resisting infection by Pseudomonas syringae (Delledonne et al. 1998). NO production may even precede the accumulation of $\mathrm{H}_{2} \mathrm{O}_{2}$, as recently observed by in vivo imaging of an elicitor-induced $\mathrm{NO}$ burst in tobacco (Foissner et al. 2000). Therefore, our findings provide another link between NO and the three components of the OCD cycle (Van Camp et al. 1998). NO was previously shown to increase SA levels (Durner et al 1998) and promote cell death (Delledonne et al. 1998), but its ability to modulate $\mathrm{H}_{2} \mathrm{O}_{2}$ levels was not determined. Thus, while future studies are required to monitor NO's effects in vivo, our results suggest a novel mechanism through which NO can stimulate the OCD cycle and activate other defense responses.

\section{ACKNOWLEDGMENTS}

We thank D. Dempsey for critical reading of the manuscript. This work was supported in part by grants MCB 9723952 and MCB 9904660 from the National Science Foundation.

\section{LITERATURE CITED}

Alvarez, M. E., Pennell, R. I., Meijer, P.-J., Ishikawa, A., Dixon, R. A., and Lamb, C. 1998. Reactive oxygen intermediates mediate a systemic signal network in the establishment of plant immunity. Cell 92:773-784.

Asada, K. 1992. Ascorbate peroxidase: A hydrogen peroxide-scavenging enzyme in plants. Physiol. Plant 85:235-241.

Brown, G. 1995. Reversible binding and inhibition of catalase by nitric oxide. Eur. J. Biochem. 232:188-191.

Chamnongpol, S., Willekens, H., Langebartels, C., Van Montagu, M., Inzé, D., and Van Camp, W. 1996. Transgenic tobacco with a reduced catalase activity develops necrotic lesions and induces pathogenesisrelated expression under high light. Plant J. 10:491-503.

Chamnongpol, S., Willekens, H., Moeder, W., Langebartels, C., Sandermann, H., Van Montagu, M., Inzé, D., and Van Camp, W. 1998. 
Defense activation and enhanced pathogen tolerance induced by $\mathrm{H}_{2} \mathrm{O}_{2}$ in transgenic tobacco. Proc. Natl. Acad. Sci. USA 95:5818-5823.

Chen, Z., Silva, H., and Klessig, D. F. 1993. Active oxygen species in the induction of plant systemic acquired resistance by salicylic acid. Science 262:1883-1886.

Dangl, J. 1998. Plants just say NO to pathogens. Nature 394:525-526.

Deisseroth, A., and Douce, A. L. 1970. Catalase: Physiological and chemical properties, mechanism of catalysis, and physiological role. Physiol. Rev. 50:319-375.

Delledonne, M., Xia, Y., Dixon, R. A., and Lamb, C. 1998. Nitric oxide functions as a signal in plant disease resistance. Nature 394:585-588

Dempsey, D. A., Shah, J., and Klessig, D. F. 1999. Salicylic acid and disease resistance in plants. Crit. Rev. Plant Sci. 18:547-575.

Durner, J., and Klessig, D. F. 1995. Inhibition of ascorbate peroxidase by salicylic acid and 2, 6-dichloroisonicotinic acid, two inducers of plant defense responses. Proc. Natl. Acad. Sci. USA 92:11312-11316.

Durner, J., and Klessig, D. F. 1996. Salicylic acid is a modulator of tobacco and mammalian catalases. J. Biol. Chem. 271:28492-28501.

Durner, J., Wendehenne, D., and Klessig, D. F. 1998. Defense gene induction in tobacco by nitric oxide, cyclic GMP, and cyclic ADPribose. Proc. Natl. Acad. Sci. USA 95:10328-10333.

Ferrer, M. A., and Ros Barceló, A. 1999. Differential effects of nitric oxide on peroxidase and $\mathrm{H}_{2} \mathrm{O}_{2}$ production by the xylem of Zinnia elegans. Plant Cell Environ. 22:891-897.

Foissner, I., Wendehenne, D., Langebartels, C., and Durner, J. 2000. In vivo imaging of an elicitor-induced nitric oxide burst in tobacco. Plant J. 23:817-824.

Hammond-Kosack, K. E., and Jones, J. D. G. 1996. Resistance genedependent plant defense responses. Plant Cell 8:1773-1791.

Hoshino, M., Ozawa, K., Seki, H., and Ford, P. C. 1993. Photochemistry of nitric oxide adducts of water soluble iron (III) porphyrin and ferrihemoproteins studied by nanosecond laser photolysis. J. Am. Chem. Soc. 115:9568-9575.

Klessig, D. F., Durner, J., Zhou, J. M., Kumar, D., Navarre, D. A. Zhang, S., Shah, J., Wendehenne, D., Du, H., Trifa, Y., Noad, R.,
Kachroo, P., Pontier, D., Lam, E., and Silva, H. 2000. NO and salicylic acid signaling in plant defense. Proc. Natl. Acad. Sci. USA 97:8849-8855

Kumar, D., and Klessig, D. F. 2000. Differential induction of tobacco MAP kinases by the defense signals nitric oxide, salicylic acid, ethylene, and jasmonic acid. Mol. Plant-Microbe Interact. 13:347-351.

Levine, A., Tenhaken, R., Dixon, R. A., and Lamb, C. 1994. $\mathrm{H}_{2} \mathrm{O}_{2}$ from the oxidative burst orchestrates the plant hypersensitive disease response. Cell 79:583-593.

Navarre, D. A., Wendehenne, D., Durner, J., Noad, R., and Klessig, D. F. 2000. Nitric oxide modulates the activity of tobacco aconitase. Plant Physiol. 122:573-582.

Nikitovic, D., and Holmgren, A. 1996. S-nitrosoglutathione is cleaved by the thioredoxin system with liberation of glutathione and redox regulating nitric oxide. J. Biol. Chem. 271:19180-19185.

Shirasu, K., Nakajima, H., Rajasekhar, V. K., Dixon, R. A., and Lamb, C. 1997. Salicylic acid potentiates an agonist-dependent gain control that amplifies pathogen signals in the activation of defense mechanisms. Plant Cell 9:261-270.

Takahashi, H., Chen, Z., Du, H., Liu, Y., and Klessig, D. F. 1997. Development of necrosis and activation of disease resistance in transgenic tobacco plants with severely reduced catalase levels. Plant J. 11:993-1005.

Van Camp, W., Van Montagu, M., and Inzé, D. 1998. $\mathrm{H}_{2} \mathrm{O}_{2}$ and NO: Redox signals in disease resistance. Trends Plant Sci. 3:330-334.

Wink, D. A., and Mitchell, J. B. 1998. Chemical biology of nitric oxide: Insights into regulatory, cytotoxic, and protective mechanisms of nitric oxide. Free Radic. Biol. Med. 25:434-456.

Wu, G., Shortt, B. J., Lawrence, E. B., León, J., Fitzsimmons, K. C., Levine, E. B., Raskin, I., and Shah, D. M. 1997. Activation of host defense mechanisms by elevated production of $\mathrm{H}_{2} \mathrm{O}_{2}$ in transgenic plants. Plant Physiol. 115:427-435.

Wu, G., Shortt, B. J., Lawrence, E. B., Levine, E. B., Fitzsimmons, K. C., and Shah, D. M. 1995. Disease resistance conferred by expression of a gene encoding $\mathrm{H}_{2} \mathrm{O}_{2}$-generating glucose oxidase in transgenic potato plants. Plant Cell 7:1357-1368. 